\title{
AVIAN SENSOR PACKAGES FOR METEOROLOGICAL MEASUREMENTS
}

\author{
Rick M. Thomas, A. Rob Mackenzie, S. James Reynolds, Jonathan P. Sadler, Ford Cropley, \\ Simon Bell, Stephen J. Dugdale, Lee Chapman, Andrew Quinn, and Xiaoming Cal
}

Two trained eagle species flew in a Scottish glen with microsensor packages to investigate the finescale variability of meteorological variables for potential use in urban areas.

$\mathrm{T}$ he paucity of meteorological data in the urban boundary layer (UBL) region above and close to building height hampers improvements in the urban component of meteorology and

affiliations: Thomas, Mackenzie, Sadler, Cropley, and CalSchool of Geography, Earth and Environmental Sciences, and Birmingham Institute of Forest Research, University of Birmingham, Edgbaston, Birmingham, United Kingdom; ReYNOLDs-School of Biosciences, University of Birmingham, Edgbaston, Birmingham, United Kingdom; Bell, Dugdale, AND Chapman-School of Geography, Earth and Environmental Sciences, University of Birmingham, Edgbaston, Birmingham, United Kingdom; QuinN-School of Engineering, and Birmingham Institute of Forest Research, University of Birmingham, Edgbaston, Birmingham, United Kingdom CORRESPONDING AUTHOR: Dr. Rick Thomas, r.thomas@bham.ac.uk

The abstract for this article can be found in this issue, following the table of contents.

DOI:10.II75/BAMS-D-16-018I.I

A supplement to this article is available online (10.1175/ BAMS-D-16-0181.2)

In final form 15 October 2017

(O2018 American Meteorological Society

For information regarding reuse of this content and general copyright information, consult the AMS Copyright Policy.

(c) (i) This article is licensed under a Creative Commons

Attribution 4.0 license. numerical weather prediction models. Since identifying the need for more measurements above the urban surface layer (Roth 2000), progress has been made particularly using surface and roof-mounted Doppler lidar to study urban wind profiles (Barlow et al. 2015). Temperature profiles are obtainable from groundbased acoustic profiling instruments (Pelliccioni et al. 2012), but their use in urban areas is limited because of the sound disturbance associated with their operation. Furthermore, the deployment of ground-based instrumentation in multiple locations is challenging because of both cost and size. However, measurements of temperature, turbulence, and humidity are required to assess the spatial variability of UBLs, the above-canopy blending heights of internal boundary layers (IBLs), and the morning and evening transitional boundary layer (Barlow 2014). Improved understanding and prediction of UBLs and IBLs have implications for (i) urban weather prediction, (ii) event forecasting (e.g., heat waves, climatic conditions during sporting events, releases of hazardous substances), (iii) air pollution modeling, and (iv) sustainable urban planning for high-density "livable" cities.

Both tethered balloons and unmanned aerial vehicle (UAV) platforms offer potential methods for deploying meteorological and chemical instruments 
on relevant horizontal and vertical scales, but the necessarily complex safety requirements for lateral beyond-line-of-sight flights currently mean that they are used most frequently in remote settings (Greatwood et al. 2017; Reuder et al. 2012; Wilcox et al. 2016) and indeed are heavily regulated around urban areas. Here, a potential alternative is demonstrated by the safe (for the general public, researchers, and the birds themselves) and humane use of captive raptors-white-tailed eagle (Haliaeetus albicilla) and Spanish imperial eagles (Aquila adalberti) - performing field tests of a miniature sensor package to measure temperature with a $5-\mathrm{Hz}$ response to a resolution of $\pm 0.2^{\circ} \mathrm{C}$. The increasing miniaturization of accurate, reliable meteorological sensors and logging systems allows the system to weigh less than $5 \%$ of the bird's body mass, a threshold much used by animal biologists partly to assess the welfare implications of treatments on animal subjects (Elliott 2016; Vandenabeele et al. 2014). The testing of a prototype package presented here using large bird species capable of carrying this mass enables the exploration of additional design refinements prior to further miniaturization. A robust, precise avian-carried sensor could be revolutionary when deployed in urban areas to address the measurement issues noted above.

This work builds on a long history of bird-human partnerships (Cocker 2013). A natural extension in such close ties is the employment of birds in scientific exercises. This applies to biologging, where devices are deployed on or in animals to investigate their behavior, physiology, and movements, as well as to capture data concerning the environment in which they move-see review by Fehlmann and King (2016). Such work started in the mid-1960s with devices attached to diving Weddell seals (Leptonychotes wedelii), but now GPS units can be deployed on birds not only to geolocate individuals but also to estimate wind velocity and convective velocity scale to generate high-resolution weather observations (Treep et al. 2016). In this paper the potential of generating accurate fast-response meteorological measurements deployed on an extended sensor suite on the back of captive raptors is investigated. The longer-term aim of the project is to miniaturize these sensors further, characterize their accuracy, and deploy them in urban areas at an unprecedented scale. The work builds on the multidisciplinary Pigeonblog environmental-justice-focused project, which used racing pigeons (Columba livia) in 2006 to carry air quality sensors in urban areas (Austen 2015). This technique was revisited by the Pigeon Air Patrol in
2016 to highlight the benefits of individual pollution exposure monitoring ( $w w w$ w.newscientist.com /article/2080835-tiny-sensors-carried-by-pigeons -can-test-air-quality-on-the-wing/). In contrast to these projects, we take a different approach, focusing first and foremost on the scientific robustness of the data, using high-quality temperature measurements coupled with our modeling expertise to challenge and improve finescale models of urban air, heat, and pollution transport. We will seek to utilize improving electrochemical sensors as the technology develops, avoiding low-quality sensors with unsolved cross-contamination issues (Lewis and Edwards 2016).

EXPERIMENTAL DESIGN. Overview. The primary experimental objective was to assess the performance of sensors on a rapid prototype device carried by eagles flying at altitudes of a few hundred meters in a steep-sided valley (locally know as a "glen"), with the aim of developing a system to provide high-quality meteorological measurements in operationally and meteorologically complex areas.

The assessment included (i) comparisons between eagle- and ground-based measurements of temperature, wind speed, and wind direction; (ii) mounting biases of the sensor and its radiation shield caused by the proximity of the sensor to the avian body; and (iii) influences on measured parameters of bird orientation relative to ground, sun, and wind direction. Additionally, it was expected that the measurements would give insights into microclimates in the glen, and information regarding the strategic and dynamic flight planning of these raptorial birds.

Raptor description. A white-tailed eagle (WTE) and a Spanish imperial eagle (SIE) carried the sensors during the flight tests. The eagles are captive birds belonging to Freedom Conservation (www.facebook .com/freedomconservation/), a Swiss organization aiming to enhance the reintroduction of the species across Europe. The birds are trained to carry small lightweight cameras and have done so for many flights with Freedom Conservation. The lowered head position during flight provides a back-mounted camera with an unobstructed view.

Site description. The site selection criteria were (i) launch and landing sites with a clear line of sight and 1-km maximum horizontal distance, allowing a clear view of the handler by the bird; (ii) a minimum of 100 $m$ of vertical extent for a good temperature-lapse-rate signal; and (iii) a road adjacent to the launch and 
landing sites for rapid support-vehicle assistance. Finding and negotiating access to a site that fulfilled these criteria and accounted for the concerns of land and wildlife stakeholders [i.e., local private landowners, Scottish Natural Heritage, the Royal Society for the Protection of Birds (RSPB)] were complicated and reflected the ongoing challenges of balancing the needs of a successful reintroduction program of wild white-tailed eagles from Scandinavia with those of landowners. The Bealach na Bà (Pass of the Cows; $57.4167^{\circ} \mathrm{N}, 5.7167^{\circ} \mathrm{W}$ ) was suggested by the RSPB because of the lack of nesting wild raptors in the local area, which might have resulted in adverse interactions with our experimental birds. Following discussions, the Applecross Estate kindly allowed access for the study.

Bealach na Bà is situated in a steep-sided glaciated hanging valley and has the greatest ascent rate of any road in the United Kingdom. A section from 381 to $575 \mathrm{~m}$ MSL offered a gradient of nearly $200 \mathrm{~m}$ over a 1-km distance and fulfilled the abovementioned criteria. Two potential eagle launch locations and a landing site were identified (locations $\mathrm{A}$ and $\mathrm{B}$ in Fig. 1) as having a sufficient vertical gradient and a clear line of sight to the landing site, with an approximately 500-m horizontal distance between the two. On inspection location B was considered the better launch site because of its ease of access.

Payload description. The Eagle Sensor Package (ESP) was designed to be within the maximum mass requirements described earlier and consisted of off-the-shelf components to measure humidity, wind speed, GPS location, pressure altitude, and movement. Table ES1 and Fig. ES1 in the electronic supplement provide further information. Also present was a beta version of an Imet-XQ (International Meteorology Systems, United States) sensor. Sensors were housed in a 3D-printed box (ESS Systems, United Kingdom) with overall dimensions of $70 \mathrm{~mm} \times 49 \mathrm{~mm} \times 38 \mathrm{~mm}$. The box contained compartments for the ESP components, and holes for the pitot tube, back, and tail sensor wires. A shield

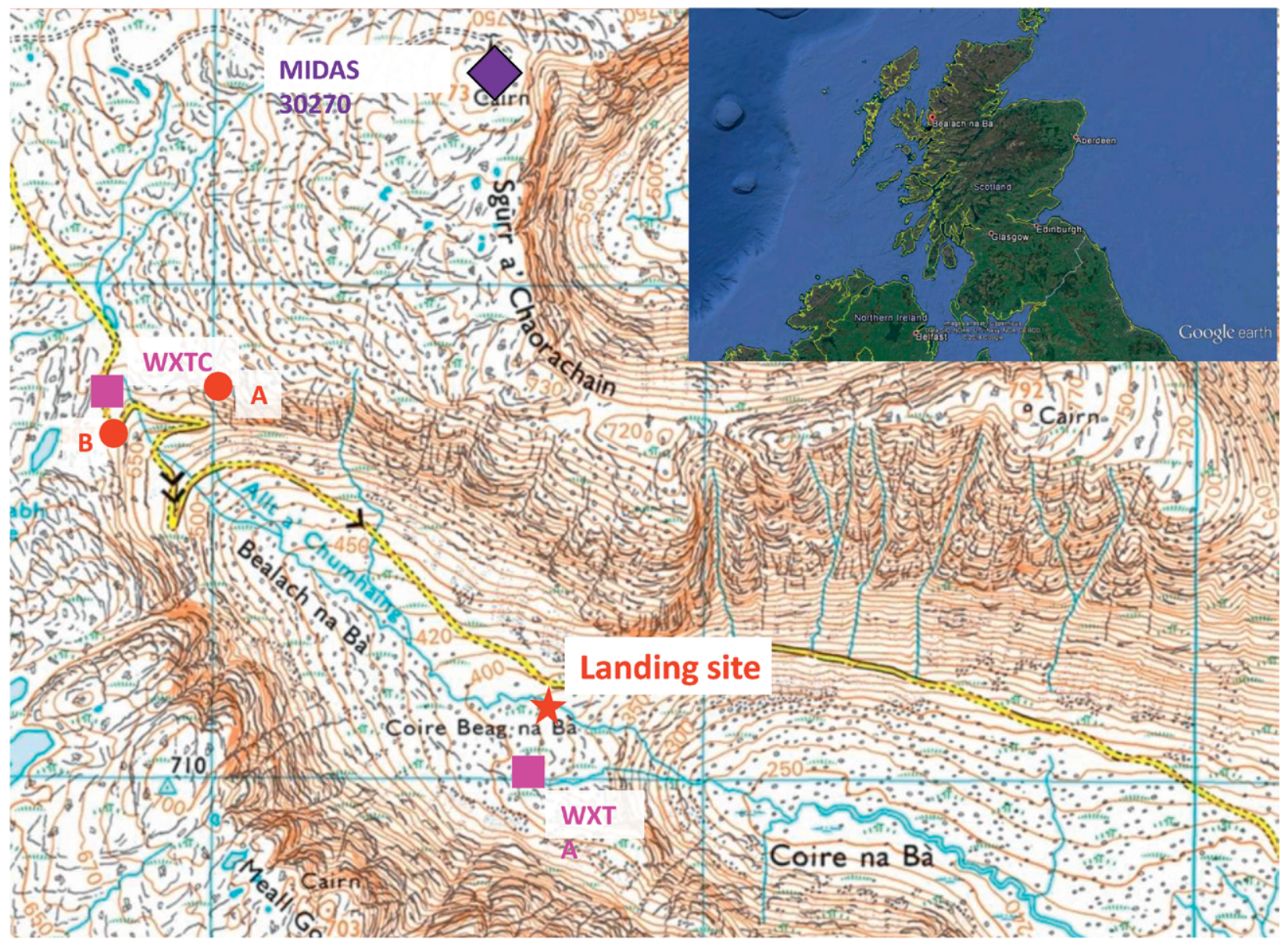

FIG. I. Plan of Bealach na Bà location (inset from Google Earth) showing eagle launch and landing sites and locations of WXT stations and METAR station 30270 (base map, from U.K. Ordnance Survey). Site B was used for releases. 
for the Fastip Probe, model 07 (FP07), thermistors (General Electric, United States) was fashioned from a white plastic straw with hinged flaps of $3 \mathrm{~mm} \times 3 \mathrm{~mm}$ cut into the sides to allow aspiration during flight. The Raspberry Pi Zero microcontroller ran Python logging code at a rate of $2 \mathrm{~Hz}$ following activation via a PC connection prior to mounting on the bird. Battery life was approximately $6 \mathrm{~h}$. This was a prototype package created to test the efficacy of the approach and the sensors. The package is undergoing further miniaturization for the next phase of deployment (see "Results and discussion" section).

Supplementary measurements. Two WXT weather stations (Vaisala, Finland) were deployed at $575 \mathrm{~m}$ MSL (WXT C) and $381 \mathrm{~m} \mathrm{MSL} \mathrm{(WXT} \mathrm{A),} \mathrm{measuring} \mathrm{tem-}$ perature, humidity, pressure, wind speed, and wind direction in 15-60-s intervals (Fig. 1). Additionally, a Skye SP1110 (Skye Instruments, United Kingdom) pyranometer was present at WXT A and a Gill R3-50 (Gill Instruments, United Kingdom) sonic anemometer recording at $20 \mathrm{~Hz}$ on a laptop were installed at the lower site. Additional meteorological information was obtained from the Met Office Integrated Data Archive System (MIDAS) surface station 30270

$\left(57.4181^{\circ} \mathrm{N}, 5.6874^{\circ} \mathrm{W} ; 773 \mathrm{~m} \mathrm{MSL}\right)$ approximately $1 \mathrm{~km}$ to the east of the launch location.

To assess the influence of heat generation by the bird and therefore inform sensor-mounting positions, thermal imagery and videos of the birds immediately after flights were taken using a FLIR A320 thermal infrared camera ( 320 pixels $\times 240$ pixels; FLIR Systems, United States) to assist with qualitative assessment of heat generated by the birds and the selection of more suitable payload locations (see supplementary material). It is accepted that the use of thermal imagery generates only qualitative data, but more detailed temperature measurements require invasive procedures to be carried out on birds with accompanying licensing implications to safeguard avian welfare.

\section{Sensor calibrations and characterizations. Details of the} calibrations of the Fastip thermistor, wind sensor, and surface-based sensors are contained in the online supplement (Table ES1). In summary, temperature sensors were compared against U.K. Accreditation Service (UKAS)-accredited sensors in a controlled temperature chamber (WKL 34/40; Weiss Technik, Belgium and Germany) and in ambient conditions at the University of Birmingham weather station [identification number (ID): 56424 ;

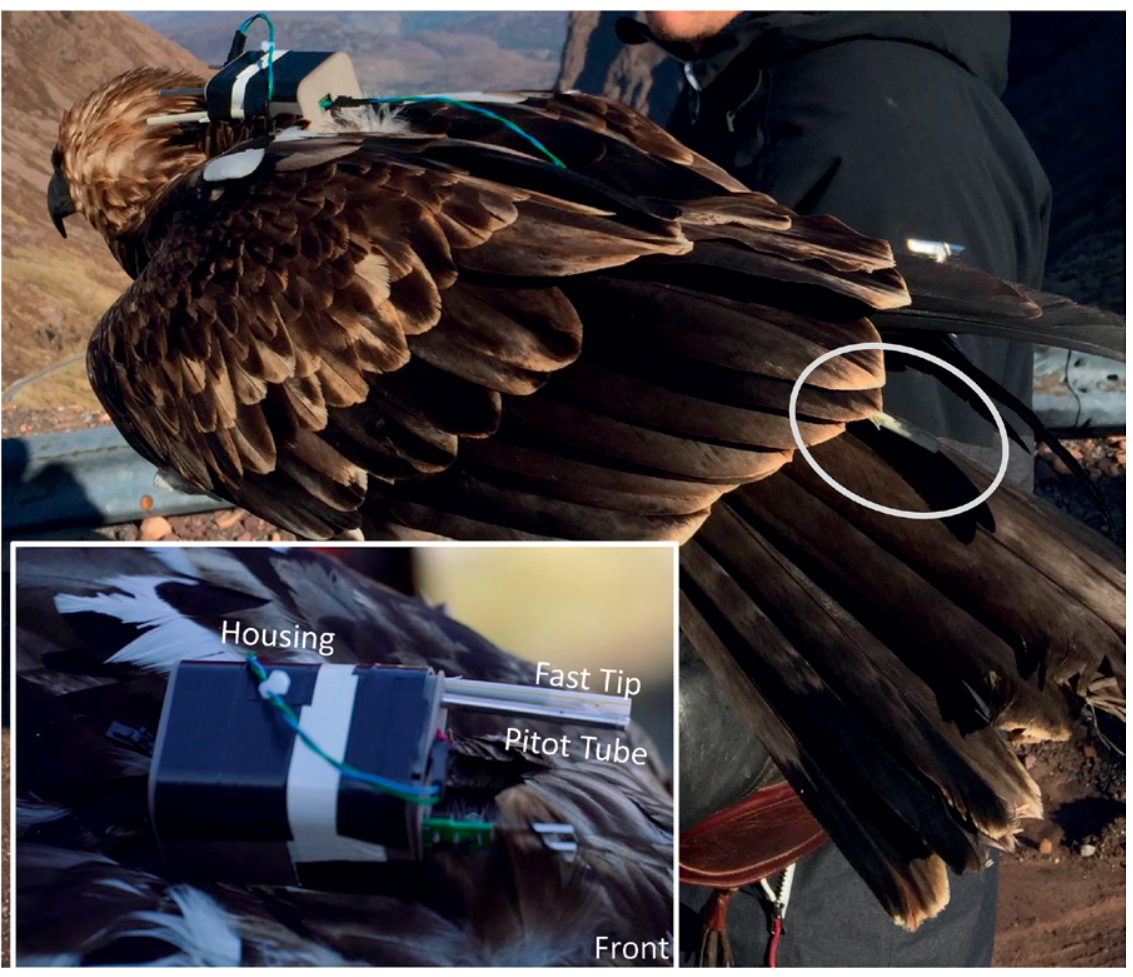

FIG. 2. Payload mounted on the back of the SIE immediately prior to FIt06A, showing the forward-facing pitot tube and $\mathrm{FT}_{\text {Back }}$ (in shield), and wire leading to $F_{\text {Tail }}$ (highlighted by the oval). FT $_{\text {Tail }}$ was carefully fitted to allow sufficient room for flight movements, while the wire was short enough to prevent entanglement. (inset) A close-up is shown of the mounted ESP and data probes. $\left.52.45636^{\circ} \mathrm{N}, 1.92765^{\circ} \mathrm{W}\right]$ (Figs. ES1 and ES2). Pitot tube wind speed calibrations were performed for the $0-8 \mathrm{~m} \mathrm{~s}^{-1}$ range in a $2 \mathrm{~m}$ $\times 2 \mathrm{~m} \times 14 \mathrm{~m}$ wind tunnel and also by comounting the pitot tube with an R3 sonic anemometer (Gill, United Kingdom) on the roof of a vehicle at wind speeds up to $25 \mathrm{~m} \mathrm{~s}^{-1}$ (Fig. ES3). A polynomial fit function was applied to the wind data and used to derive wind speeds (Fig. ES4). Pressure altitude corrections were made using the altitudes of WXT A and WXT B from the U.K. Ordnance Survey data as reference points. During field measurements, the data from WXT stations were used as the primary calibration standard and to reference the Fastip sensors following each flight. 
Payload mounting and operation. The ESP was mounted on the birds by Freedom Conservation using their veterinarian-approved attachment method. This proprietary technique enables them to mount highquality video cameras stably to capture commercially viable footage. It was anticipated that the tailmounted sensor, being distal from the thermogenic central core of the bird's body, would be less prone to detection of heat generated by the flying bird. To investigate this, a temperature sensor (additional to the back-mounted one) was mounted on the tail of the SIE using a mount clip and connected to the ESP with a $3-\mathrm{mm}$ wire. It was deployed carefully to allow sufficient movement for flight, and the connecting wire was short enough to prevent entanglement. Figure 2 shows the mounted sensor package with the wire leading to the tail temperature sensor prior to the flight. The pitot tube was oriented forward to measure wind over the back of the bird when flying in a horizontal head-down position. The logger was attached and activated at a car park area near WXT A. The bird was then driven to the launch point and released within $15 \mathrm{~min}$. The birds did not display aberrant behaviors, such as a reluctance to take off or overinvestment in preening efforts at sites where the ESP device was located.

RESULTS AND DISCUSSION. Ambient meteorological conditions. The weather between 6 and 8 May 2016 was typical for the time of year in northwest Scotland-temperatures of $3^{\circ}-9^{\circ} \mathrm{C}$, relative humidity of $>60 \%$, 1-min mean wind speeds of $0-14 \mathrm{~m} \mathrm{~s}^{-1}$, and incoming solar radiation $S_{N}$ below $320 \mathrm{~W} \mathrm{~m}^{-2}$. Rainfall events occurred on the night of 5 May and overnight on 7-8 May. The weather and time of day of these four flights provided near-neutral stratification conditions for the altitudes where the birds were flying. Therefore, the vertical temperature lapse rates were expected be close to the dry-adiabatic lapse rate of $9.8^{\circ} \mathrm{C} \mathrm{km}^{-1}$, and this was demonstrated by the temperature data from two weather stations, WXT C and WXT A (Table 1). The slightly smaller lapse rate for the second late afternoon flight on 6 May 2016 (Flt06B) was attributed to a drop of about $0.5^{\circ} \mathrm{C}$ at WXT A, which at this time of day was located in the shadow of the glen, where it may therefore have been subject to the effect of longwave radiation cooling. This is confirmed by a large drop in $S_{N}$ from 319 to $42 \mathrm{~W} \mathrm{~m}^{-2}$ occurring between the two flights.

Flight characteristics. Four flights were conducted, two with the SIE in late afternoon (1700-1716 UTC) of 6 May 2016 (Flt06A and Flt06B) and two with the

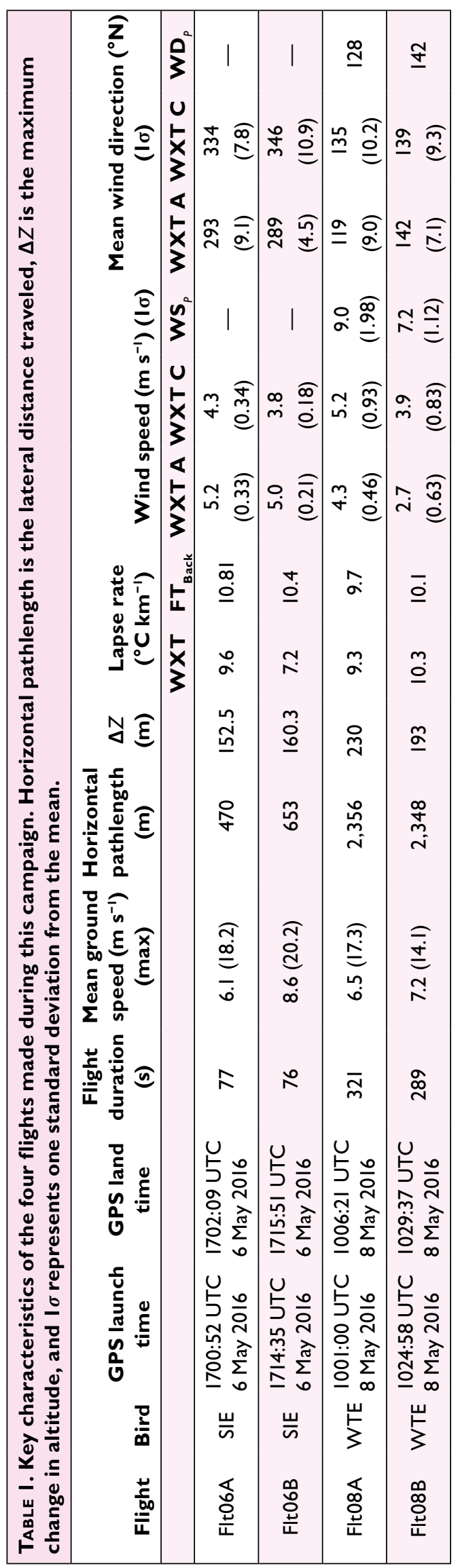


WTE on the morning (1000-1030 UTC) of 8 May 2016 (Flt08A and Flt08B), as shown in Figs. 3a and $3 \mathrm{~b}$, respectively. With respect to bird release and recapture, all flights went according to plan-upon release the birds broadly followed the line of the glen southeast to the handler. Figure 4 shows flight data collected from the ESP, with a summary of the flight characteristics provided in Table 1. Keyhole Markup language (KML) files for viewing flight traces in Google Earth are available in the online supplement.

Flights Flt06A and Flt06B lasted for just over a minute each, assisted by the WXT-measured tail wind coming from $280^{\circ}$ to $360^{\circ}$ (Fig. $4 \mathrm{a}$; Table 1) with wind speed from 3.8 to $5.2 \mathrm{~m} \mathrm{~s}^{-1}$ (Table 1). In general, Flt06A shows a line with little deviation from a path descending slowly through the central line of the glen (Fig. 3a), followed by a more rapid descent to the handler. The vertical accelerometer data $a_{z}$ (Fig. 4a) denoted the lift off at 1700:52 UTC and the SIE headed east. Subsequent vertical oscillations are characterized as wingbeats (Portugal et al. 2014). Initially, after some drop in altitude (Fig. 4a) of $30 \mathrm{~m}$, these wingbeats were infrequent but then increased, helping the bird to maintain altitude and to increase ground speed between 1701:05 and 1701:15 UTC. After this time, flight direction was changed to a southeasterly heading, the wingbeats ceased, and ground speed rapidly increased together with a decreasing wind speed over the bird's back $\left(\right.$ Wind $\left._{\mathrm{Bk}}\right)$; this indicates an alignment with the local wind direction, shown broadly to follow the strike of the glen by WXT A and WXT C (Fig. 4a). After 1701:26 UTC, a gentle descent took place, with GPS heading arrows showing rotations around the handler (Fig. 4a) as the SIE circled from above and landed. This latter half of Flt06A showed a reduced GPS ground speed, as altitude was lost and lateral movement relative to the ground was reduced. In Fig. 4a Wind $_{\mathrm{Bk}}$ is approximately $14.5 \mathrm{~m} \mathrm{~s}^{-1}$ for the majority of the flight despite changes in ground speed, indicating near-constant positive wing loading. Similar results were found in flights of steppe eagles (Aquila nipalensis) by Gillies et al. (2011).

Flt06B (Fig. 4b) showed a similar altitude profile to Flt06A, but the profile (Fig. 3a) shows the bird taking a more exploratory flight path that closely followed the contours of the northeastern glen side. This caused the GPS signal to deteriorate, resulting in patchy positional data. During the final descent from an altitude of $472 \mathrm{~m}$ MSL at 1715:20 UTC the SIE struck out south across the glen. The ground speed approached $0 \mathrm{~m} \mathrm{~s}^{-1}$ while the wind speed measured by the sensor remained at $15 \mathrm{~m} \mathrm{~s}^{-1}$. This indicated that the SIE slowed position in the center of the glen, prior to descending, as was further evidenced by the lack of wingbeats during this time (detected from $a$ ).

WXT data indicated that the wind direction on 8 May 2016 was the reverse of that on 6 May 2016 with directions of $128^{\circ}$ and $141^{\circ}$ from WXT A and WXT $\mathrm{C}$, respectively, and wind speeds of 3.5 and $5.1 \mathrm{~m} \mathrm{~s}^{-1}$, respectively (Fig. 4c; Table 1). This up-slope direction contributed to the longer flights of the WTE, both of which lasted over $5 \mathrm{~min}$. After the Flt08A release at 1001:00 UTC, the WTE gained about $37 \mathrm{~m}$ in altitude traveling into the wind, and with a relative $\mathrm{Wind}_{\mathrm{Bk}}$ of $15 \mathrm{~m} \mathrm{~s}^{-1}$ and a ground speed of $5 \mathrm{~m} \mathrm{~s}^{-1}$, few wingbeats were undertaken. When wingbeats occurred (e.g., at 1002:19, 1002:36, and 1004:12 UTC), they coincided with increased wind speed registered by the pitot tube on his back. The GPS trace of this flight (Fig. 3b) shows a line taken where the WTE followed the contours of the southern side of the glen, maintaining

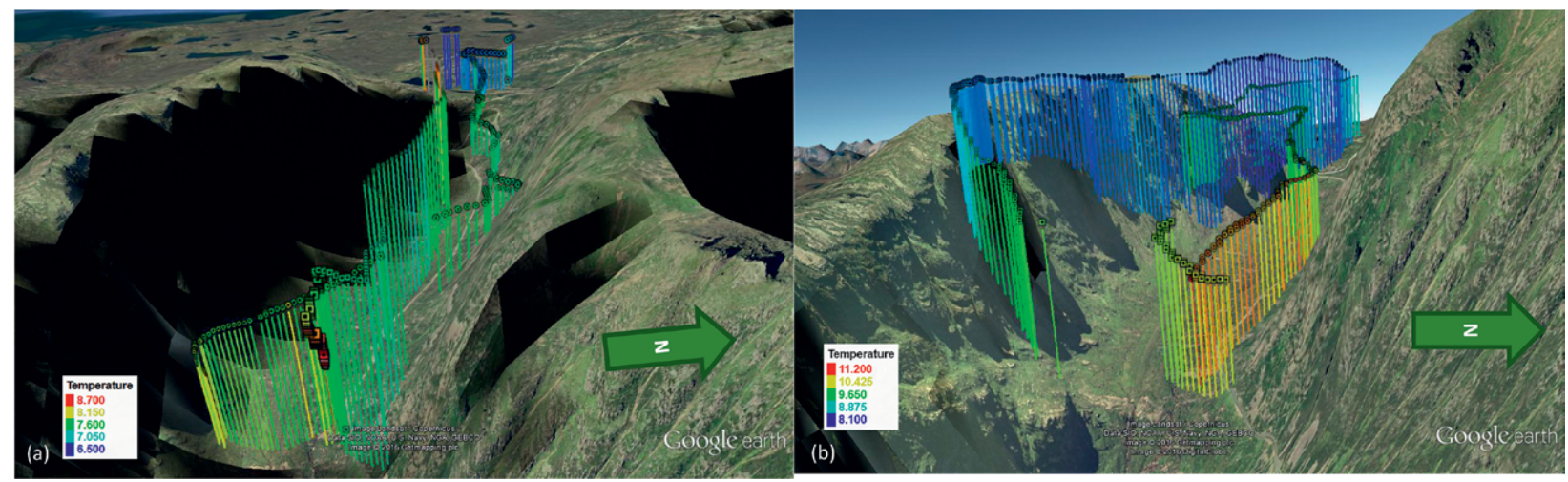

Fig. 3. GPS traces of (a) Flt06A (squares) and Flt06B (circles) on 6 May 2016 and (b) Fit08A (squares) and Flt08B (circles) on 8 May 2016. Colors represent temperature, and size of marker represents ground speed. To avoid terrain, all traces have been moved vertically upward by $100 \mathrm{~m}$, and Flt06B, being particularly close to the cliff, has been moved south by $\mathrm{III} \mathrm{m}\left(0.00 \mathrm{I}^{\circ}\right.$ latitude). Shadows are Google Earth's representation of the conditions at 1715 UTC 6 May and 1015 UTC 8 May. 
an altitude of 575-612 m MSL. During this phase, ground speed fluctuated to near zero as the flight direction was reversed (see GPS heading arrows in top plot of Fig. 4c). The final stage of this flight was a rapid descent from $564 \mathrm{~m}$ MSL to the handler at the surface (381 m MSL) in $26 \mathrm{~s}$. During the descent the maximum Wind ${ }_{\mathrm{Bk}}$ was $29.2 \mathrm{~m} \mathrm{~s}^{-1}$.

The final test flight profile, Flt08B (Fig. 3b), began in a southeasterly heading and a 5-m altitudinal descent, again closely following the southerly glen wall. The ambient wind speed had dropped by this time, with WXT C, WXT A, and the sonic anemometer providing maximum wind speeds of $3.6 \mathrm{~m} \mathrm{~s}^{-1}$ (Fig. 4d) compared with $6 \mathrm{~m} \mathrm{~s}^{-1}$ after the takeoff phase of Flt08A $\left(\right.$ Wspd $\left._{\text {son }}\right)$. Following takeoff, the WTE turned $180^{\circ}$ and flew northwest back up the glen. Flying with the ambient wind direction increased ground speed and required wingbeats to maintain airspeed, as seen between 1026:24 and 1026:43 UTC. At this point, the WTE landed on the northwest face of the glen wall, approximately $50 \mathrm{~m}$ below the launch site. Being the fastest to respond, $a_{z}$ settled to $0 \mathrm{~g}$-force first, the pitot tube recorded Wind ${ }_{\mathrm{Bk}}$ consistent with the ambient wind measured at WXT C (next to launch site), and the GPS ground speed averaged to zero. After $18 \mathrm{~s}$ the WTE took off again and the flight path followed a gentle descent to the handler at a descent rate of $1.6 \mathrm{~m} \mathrm{~s}^{-1}$.

Fastip and shield time responses. By interpreting flight direction, body movement, and location within the glen, the flight descriptions mentioned above aid interpretation of vertical temperature profiles, as shown in Figs. 5a-d for the four flights.

Looking first at the eagle Fastip (FT) temperature profiles for FLT06A (Fig. 5a), there was an adjustment period to the ambient temperature profile following takeoff between altitudes of 575 and $538 \mathrm{~m}$ [backmounted FT $\left.\left(\mathrm{FT}_{\text {Back }}\right)\right]$ and between 575 and $495 \mathrm{~m}$ MSL [tail-mounted FT $\left(\mathrm{FT}_{\text {Tail }}\right)$ ]. Figure $4 \mathrm{a}$ shows that the times to these altitudes were 36 and $80 \mathrm{~s}$ for $\mathrm{FT}_{\text {Back }}$ and $\mathrm{FT}_{\text {Tail }}$, respectively. Similar times of 14 and $77 \mathrm{~s}$ were recorded for Flt06B $\left(\mathrm{FT}_{\text {Back }}\right.$ and $\mathrm{FT}_{\text {Tail }}$, respectively). These differences are attributable to sensor heating when stationary as a result of proximity to the bird's body, combined with insufficient shield ventilation. In the minute prior to takeoff of Flt06B, $\mathrm{FT}_{\text {Back }}$ temperature fluctuated between $8.8^{\circ}$ and $12^{\circ} \mathrm{C}$ and $\mathrm{FT}_{\text {Tail }}$ temperature fluctuated between $9.1^{\circ}$ and $10.1^{\circ} \mathrm{C}$ (not shown), reflecting differences in sensor aspiration as a result of changes in the bird's orientation prior to launch. Additionally, feather insulation of the tail-mounted sensor reduced aspiration and insulated the device; hence, a slower response time in $\mathrm{FT}_{\text {Back }}$ compared to the back-mounted sensor (Fig. 5a). For the second flight (Fig. 5a), there is a better agreement between $\mathrm{FT}_{\text {Back }}$ and $\mathrm{FT}_{\text {Tail }}$, with more turns and a slower descent rate improving the aspiration by the ambient wind.

On 8 May 2016 temperature fluctuations (between $7.9^{\circ}$ and $10.3^{\circ} \mathrm{C}$ ) also occurred in the minute before takeoff (not shown), but the orientation of the sensor shield opening into the up-slope wind on this occasion allowed $\mathrm{FT}_{\text {Back }}$ to be adequately ventilated prior to takeoff, resulting in no apparent lag period for Flt08A and Flt08B. However, this effect was seen during the 18-s perch; the Fastip temperature sensor registered an increase of $1.7^{\circ} \mathrm{C}$, adjusting to ambient background temperature again within $4 \mathrm{~s}$ of takeoff (Fig. $4 \mathrm{~d}$ ).

Finally, Fig. 4 also shows ambient solar radiation $S_{N}$ from WXT A at the recovery location. The value dropped markedly from over 300 to $<50 \mathrm{~W} \mathrm{~m}^{-2}$ following shading as the southern valley wall shadow fell across the sensor between flights Flt06A and Flt06B. The solar radiation on 8 May 2016 was also low given the time of year, registering values of up to $270 \mathrm{~W} \mathrm{~m}^{-2}$.

Temperature profiles and environmental lapse rates. Using temperature data from the MIDAS station 3039 at $773 \mathrm{~m} \mathrm{MSL}$, the WXT station data fall neatly on the extended profile (Fig. 5a, inset) with a lapse rate of $9.6^{\circ} \mathrm{C} \mathrm{km}^{-1}$. Below $538 \mathrm{~m} \mathrm{MSL}$, once adjusted to the ambient temperature, $\mathrm{FT}_{\text {Back }}$ showed a linear profile with a lapse rate of $10.8^{\circ} \mathrm{C} \mathrm{km}^{-1}$ for Flt06A (Fig. 5a), which compares favorably with that from the surface stations (i.e., $9.6^{\circ} \mathrm{C} \mathrm{km}^{-1}$ ) (Table 1). The $\mathrm{FT}_{\text {Back }}$ mean lapse rate below $522 \mathrm{~m} \mathrm{MSL}\left(10.4^{\circ} \mathrm{C} \mathrm{km}^{-1}\right)$ from Flt06B conflicted with the WXT profile, indicating less unstable conditions $\left(7.2^{\circ} \mathrm{C} \mathrm{km}^{-1}\right)$, with the change mainly driven by a temperature drop at WXT A. This is attributed to the encroaching cliff shadows in the glen described in the ambient meteorology section. With more uniform solar radiation across the glen on 8 May, lapse rates from flights Flt08A and Flt08B ( 9.7 and $10.1^{\circ} \mathrm{C} \mathrm{km}^{-1}$, respectively) agreed more with WXT-derived values for the same flight periods $(9.3$ and $10.3^{\circ} \mathrm{C} \mathrm{km}^{-1}$, respectively; Table 1 ).

The 20-s dive of Flt08A (Figs. 4c and 5c) from 1005:10 to 1005:30 UTC capturing most of the temperature sounding at the end of Flt08A appeared to confirm the rapid response time of the $\mathrm{FT}_{\text {Back. }}$. With wind speeds approaching $30 \mathrm{~m} \mathrm{~s}^{-1}$, the temperature sounding slope displayed a neutral profile with the dry-adiabatic value of about $10^{\circ} \mathrm{C} \mathrm{km}^{-1}$ between 440 and $525 \mathrm{~m} \mathrm{MSL}$. If the time response of the ESP was too slow, a steeper curve (a smaller temperature lapse 

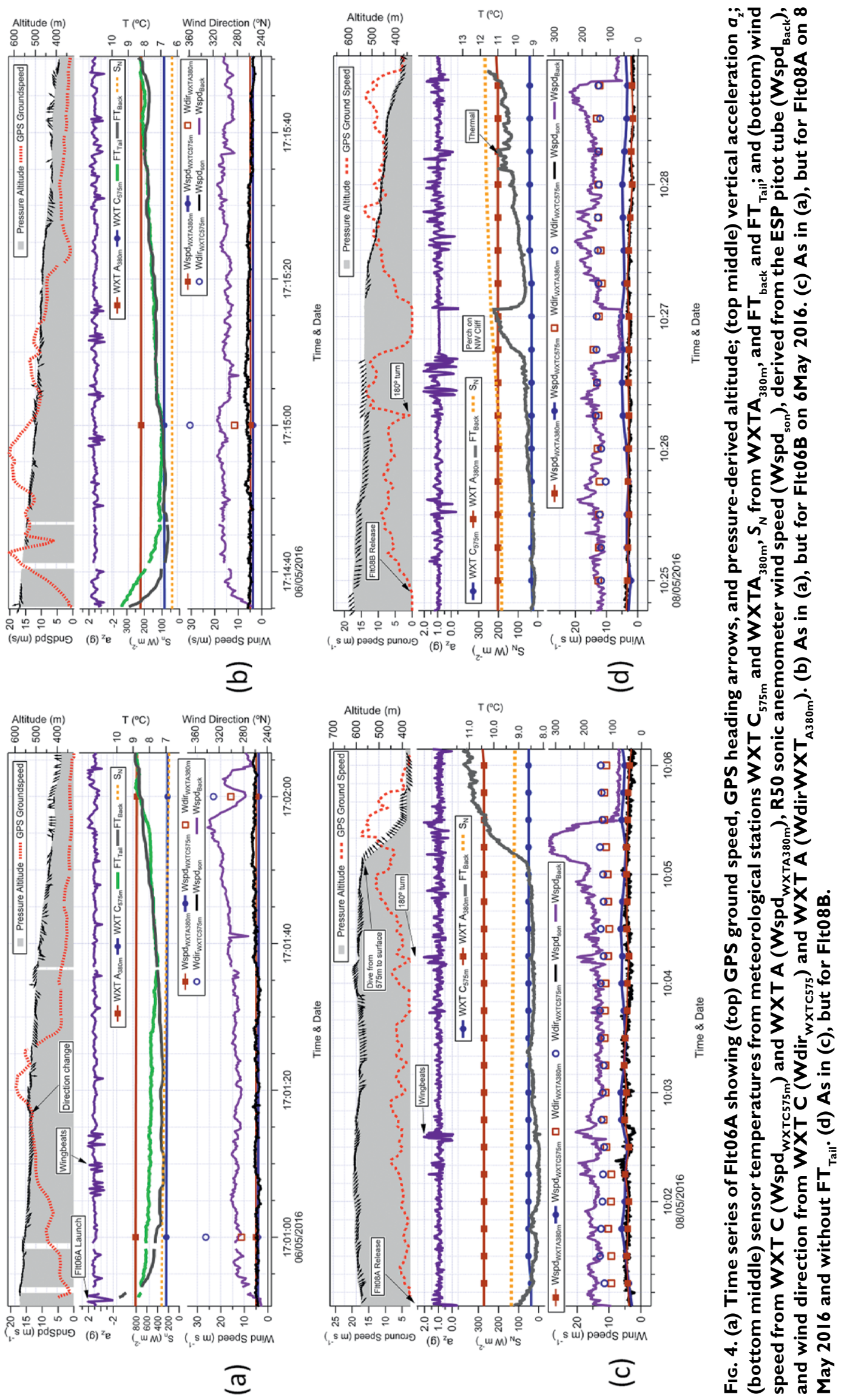




WXT Stations MIDAS 30270

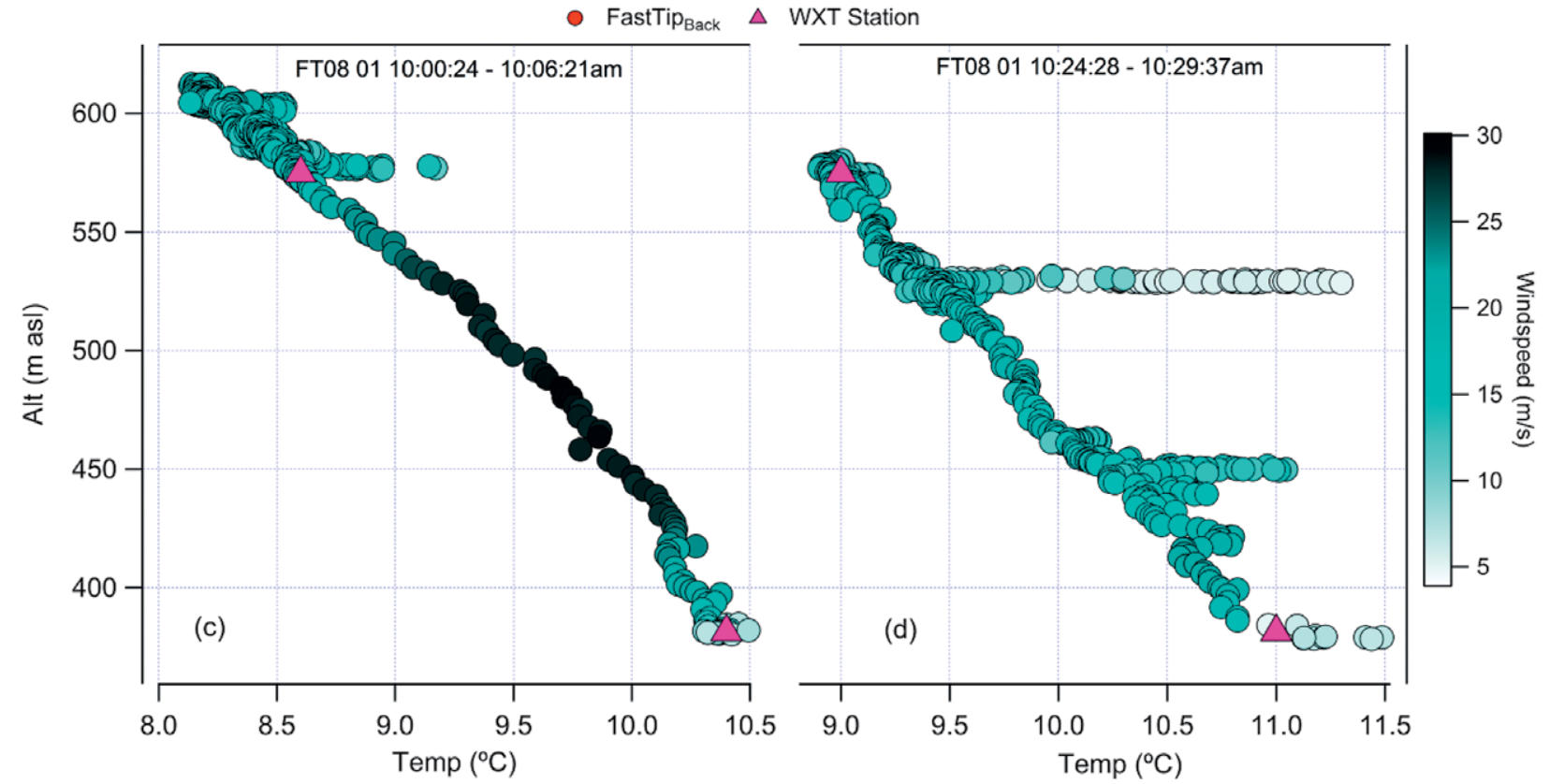

Fig. 5. Vertical temperature profiles for flights (a) Flt06A, (b) Flt06B, (c) FIt08A, and (d) Flt08B. (a),(b) FT back' $^{\text {'t }}$ FT $T_{\text {Tail }}$ (shaded by wind speed from pitot tube), and WXT stations. (c),(d) FT Tail $_{\text {(shaded by wind speed from pitot }}$ tube). WXT stations are indicated (pink squares). The inset in (a) is FT $T_{B a c k}, W X T$ stations, and METAR station temperature profile.

rate) than the dry-adiabatic lapse rate is expected. In fact, during an early phase of the dive-namely, from 570 to $525 \mathrm{~m} \mathrm{MSL}$ - the measured lapse rate is slightly above the dry-adiabatic value. This can only be explained by the presence of a weakly unstable stratification layer. Meanwhile, it indicates a fast response of the ESP when airflow around the ESP is sufficiently high. Toward the end of the dive between
$425 \mathrm{~m} \mathrm{MSL}$ and the landing site, the airflow speed was lower $\left(<10 \mathrm{~m} \mathrm{~s}^{-1}\right)$ and measured temperatures did not change much, suggesting the sensor was not sufficiently aspirated to provide reliable data.

Glen microclimate investigation. Flt06A provided the fewest deviations in the temperature trace; the slow descent through the middle of the glen revealed 
little temperature variation, and the low wind speed of approximately $15 \mathrm{~m} \mathrm{~s}^{-1}$ indicated a steady aspiration of $\mathrm{FT}_{\text {Back }}$. FT06B (Fig. 3a), by contrast, reflects a flight path that more closely follows the contours of the cliffs, and the microclimates that develop in those areas following a day of radiative heating and most likely caused the temperature variation seen in the (particularly $\mathrm{FT}_{\text {Back }}$ ) Flt06B profile (Fig. 5b). However, in both Flt06A and Flt06B, FT ${ }_{\text {Back }}$ and FTTail display a temperature increase of approximately $0.5^{\circ} \mathrm{C}$ at $400-420 \mathrm{~m}$ MSL. The time trace (Figs. $4 \mathrm{a}, \mathrm{b}$ ) indicates these events occurred at 1702:00 UTC for Flt06A and 1715:42 UTC for Flt06B and are associated with a slight increase in altitude and a northerly orientation. This indicates an interaction with the surface wind layer by the SIE when controlling the approach to the handler.

The slower descent rate by the bird during Flt08B allowed the ESP to detect finer-scale meteorological features than environmental lapse rates. Aside from the warming measured during the break in flight at $529 \mathrm{~m} \mathrm{MSL}$, there was also warming seen at $451 \mathrm{~m}$ MSL (Fig. 5d) when the bird was in motion. The time trace of $\mathrm{FT}_{\text {Back }}$ (Fig. 4d) indicated the latter took place just after 1028 UTC, when altitude leveled off, immediately followed by wingbeats declining to nearzero frequency. This implies a temperature increase caused by a warm updraft, probably associated with the hanging valley lip, which the WTE utilized to glide to a landing thereafter.

Pitot tube analysis. Wind speed from the back of an eagle is not an easy measurement to make: the pitot tube is valid when orientated within approximately $20^{\circ}$ of the true airflow direction; the dynamics of bird flight routinely decouples the heading and sideslip directions, and there may be flow distortion as a result of the bird's morphology. Using flight data from 8 May, which were into the up-slope ambient wind measured by the WXTs, we explore a method to derive the ambient wind vector. We first applied the calibration polynomial to the sampled voltages to derive a wind speed local to the bird, subtracted the GPS ground speed to obtain a local wind speed, and removed data points based on simple but logical flight limits comprising vertical and lateral translation rates (to ensure sufficient horizontal wind flow and to exclude dives during flights) and attitude (to include straight and level data). These we define as $-2<$ ascent speed $<2 \mathrm{~m} \mathrm{~s}^{-1}, 4 \mathrm{~m} \mathrm{~s}^{-1}<$ GPS ground speed, and $0.5<a_{z}<1.5 \mathrm{~g}$-force, respectively. Filtered data were between 560 and $650 \mathrm{~m}$ MSL. Figure 6 and Table 1 present filtered pitot-derived local wind speeds $\left(\mathrm{WS}_{P} \mathrm{~s}\right)$ against wind direction $\left(\mathrm{WD}_{P}\right)$ binned into $15^{\circ}$ intervals for flights on 8 May, where $n \geq 3$ for each bin. Also plotted are the WXT A and WXT B stations for 575 and $371 \mathrm{~m}$ MSL, respectively.

We expected to see a peak in the pitot signal when it was aligned with the mean wind, and while our data include points where the bird may be oriented away from the true airflow during flight, the maximum peaks we see in $\mathrm{WD}_{P}$ for Flt08A and Flt08B (128 and 142 , respectively) corresponded with those from the WXTs for the same period, with an apparent veering between the two flight times. The magnitude of the wind speed $\left(7-9 \mathrm{~m} \mathrm{~s}^{-1}\right)$ reflected the increased altitude of the ESP and was below that of $13.5 \mathrm{~m} \mathrm{~s}^{-1}$ measured at the aviation routine weather report (METAR) station between 1000 and 1100 UTC. The 25\%-37\% decrease in WXT wind speed was reflected in the 20\% decrease of $\mathrm{WS}_{P}$ between flights. From this limited dataset we conclude that this offers an approach that is worthy of further development.

SENSOR PACKAGE ASSESSMENT. Under the dynamic meteorological conditions encountered in this Scottish glen, ESP "flight envelopes" can be constructed. The ESP performed well for temperature soundings, provided the sensor and its radiation shield are constantly aspirated between 10 and $20 \mathrm{~m} \mathrm{~s}^{-1}$. The beta version of a commercial small humidity sensor failed to collect data during the flights, and future ESP designs will incorporate a fastresponse humidity sensor. The pitot tube improved interpretation of the temperature data through direct measurement of wind flow over the birds' backs and indicated that measurement of ambient wind is possible and will improve with data points from longer flights, providing data in all wind directions and by adding integrated magnetometer data for improved bird orientation. With longer flights, the data can also be coupled with GPS traces to measure ambient wind speed and direction accurately (e.g., Treep et al. 2016). Further miniaturization of the pitot tube is being assessed.

For microclimate investigation when in proximity to vertical solid surfaces, such as cliff faces, positional and accelerometer data assist interpretation; these microclimates contrast markedly with those from clear profiles, such as in the middle of the glen. Micrometeorological features appear to register in the ESP when the descent rate is $<2.6 \mathrm{~m} \mathrm{~s}^{-1}$ (taken from the descent rate when the thermal feature was measured in Flt08B).

In contrast to our initial expectations, tail mounting of temperature sensors was not found to be ideal. 


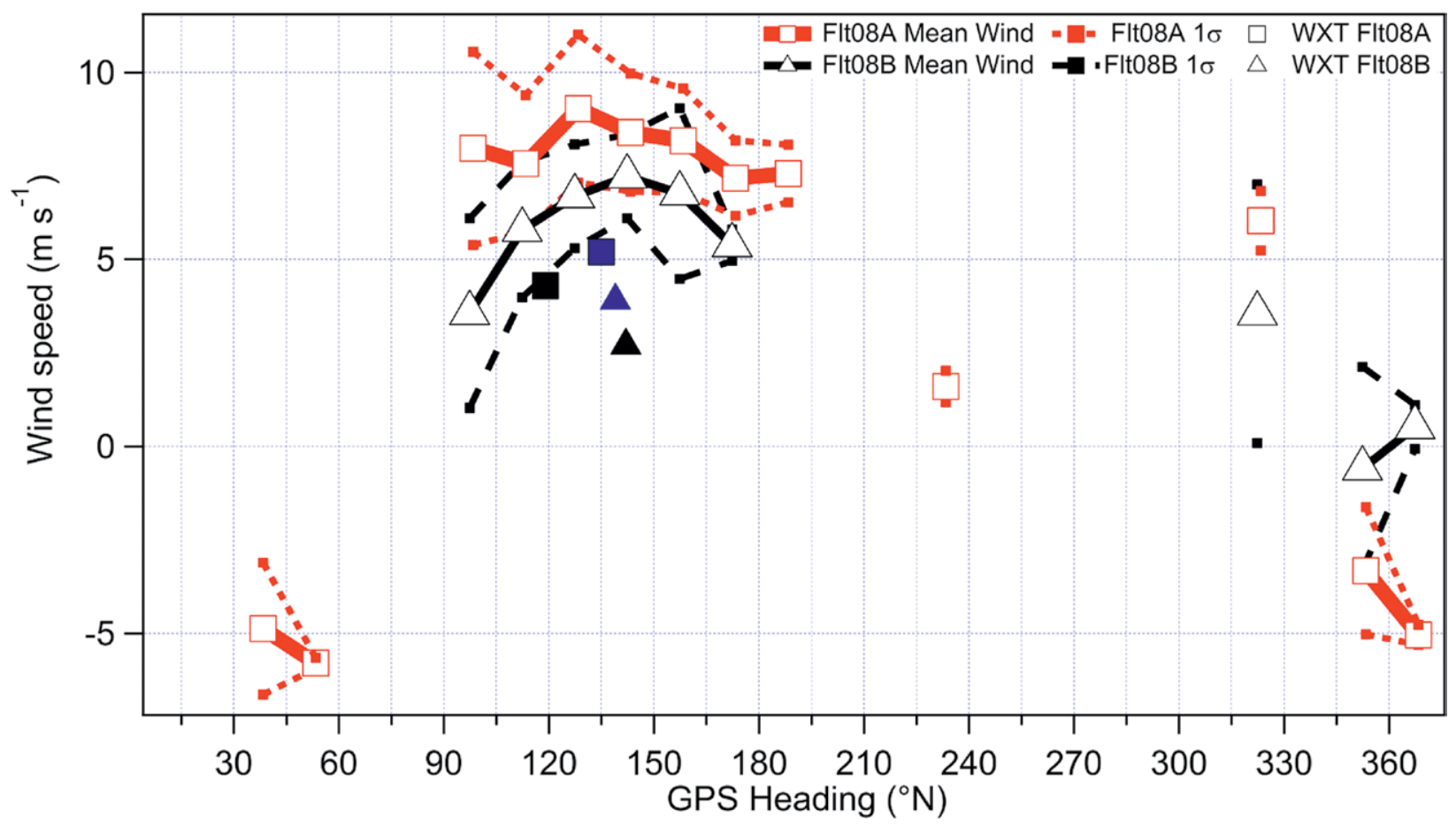

FIG. 6. Filtered mean local wind speed derived from the pitot tube data binned into $15^{\circ}$ intervals (where $n \geq 3$ for each bin) for flights on 8 May 2016. Filters are defined as $-2<$ ascent speed $<2 \mathrm{~m} \mathrm{~s}^{-1}, 4 \mathrm{~m} \mathrm{~s}^{-1}<\mathrm{GPS}$ ground speed, and $0.5<a_{z}<1.5$ g-force (I g-force when level), respectively. WXT data for FIt08A (squares) and Flt08B (triangle) at 575 (blue) and 37 I (black) $\mathrm{m}$ MSL are also shown.

Sensor performance can be disrupted by unquantifiable shielding from tail feathers that are susceptible to inputs, such as dirt and moisture, that will further disrupt sensor functionality. Moreover, as birds use tail feathers in flight for maneuvering (Thomas 1993), the sensors are subjected to considerable disturbance. Thermal imagery of the SIE following Flt06A showed (qualitatively) the head at approximately $22^{\circ} \mathrm{C}$, warm wing muscles, and a cooler tail by approximately $9^{\circ} \mathrm{C}$ (Fig. ES5). In contrast, the back-mounted sensor was not susceptible to body heat derived from the bird, provided that it was moving at $>10 \mathrm{~m} \mathrm{~s}^{-1}$ to aspirate the solar radiation shield. Observations in this study support those of Gillies et al. (2011), which reveal that eagles maintain a positive wing loading and a wind speed of $15-20 \mathrm{~m} \mathrm{~s}^{-1}$. These flight features will be used to inform an improved design of a lightweight shield to provide greater airflow in a wider range of orientations and wind speeds. It could be possible to modify this portion of the sensor to be an extension of existing tags deployed on wild birds.

Birds of prey, such as eagles, are not long-distance flyers but employ thermals during soaring flights. Their large wings allow reduced investment of energy per unit time, through slow flights and consequently low wing loading (Tennekes 1996). Flight data from free-flying eagles are scarce, but Gillies et al. (2011) deployed inertial units on a steppe eagle that flew on 15 separate flights launched into the wind from an elevated position. They showed that all flights consisted of a series of banked turns punctuated by wing tucks and rollover maneuvers. Wind direction, wind speed, and air temperature may be key determinants of these eagle flight characteristics: wind direction in opposition to bird flight direction allows for a more sustained flight and thermal development promotes soaring. Our two eagles exhibited similar flight responses to wind direction on their test flights. Sensors were rigidly mounted on the birds, which allows measurements of bird movements relative to the ground and provides good indication of the timing (and thus frequency) of wingbeats (Portugal et al. 2014). Care should be exercised when deploying sensors on birds using alternative mounting methods because the ESP must be fixed on the bird's surface to avoid excessive movement. In addition, alternative deployment modes may cause discomfort to the bird through, for example, restriction of free movement during flight, that would inevitably result in ethical questions about the suitability of the deployment in the first place (cf. Elliott 2016). As a rule of thumb that we followed in this study, a sensor should always be no more than $2 \%-5 \%$ of the body mass of the bird carrying it and it should not be deployed in such a way that 
it significantly influences the bird's normal behavior patterns (Fehlmann and King 2016). Furthermore, movement of the ESP relative to the bird itself would undoubtedly result in spurious representations of the bird's flight characteristics and compromise sensor accuracy. Finally, consideration should be given to biases introduced by the bird itself because its flight strategies are optimized for local conditions (Treep et al. 2016), seen here during the birds' utilization of thermals and local winds. Ultimately, the biology of the bird dictates when and where they should be deployed for such research.

TOWARD URBAN MEASUREMENTS. When freely living, birds may not choose or they may be unable to fly in certain meteorological conditions (e.g., low winds, high wind shear). Understanding more about the flight strategies of these avian "platforms" for the sensors will allow their flight capabilities to be harnessed to probe maximally the meteorological feature(s) of interest. Shepard et al. (2016) have begun this process by investigating airflow in urban areas by remotely observing gull interactions with airflow around buildings. Although, the present study used raptorial species at a remote (nonurban) location, it is reasonable to propose that raptors carrying our sensors be used for meteorological work in urban centers. After all, raptors are increasingly observed in our towns and cities, and their abundance and movements within cityscapes are predicted to rise (Bird et al. 1996). Pigeons are also a possible species for carrying a smaller version of the ESP payload and we are investigating this approach.

When transferring this technique to other situations, there are some operational limitations to consider. The 5\% payload limit has been discussed above and is a matter of increasing technological development and miniaturization. An issue inherent to all animal-based measurement techniques is a lack of control over the exact location where data are collected. With raptor and homing pigeon flights, the release and recapture positions are defined, but not the route between the two positions. This lends itself to research applications where the vertical profile of a horizontally homogeneous atmosphere is of interest. In this situation the horizontal positions are less important. In a heterogeneous atmosphere (e.g., an UBL), a cluster approach using a flock of birds may yield a more useful dataset, although, again, individual flight paths are not defined. Currently, it is unlikely that we can apply this technique to nighttime stable layers, but it can be used on the occasions where stable layers occur in the day, or to investigate morning, or urban to rural, transitions. For comparison, UAV use also requires licensing and while it is possible to decide on the exact flight path with a UAV, it is not easy to fly them over long distances across urban airspace or at night for the investigation of nocturnal boundary layers.

CONCLUSIONS AND OUTLOOK. This project made robust temperature sensor profiles using accurate fast-response sensors mounted on the backs of two captive eagles. In addition, our sensor package contained a pitot tube and demonstrated the potential for the derivation of wind speed and direction.

Our next steps are to continue to reduce the payload weight and to work toward flights in urban areas, for use on other species. We have produced a $21-\mathrm{g}$ payload version for temperature and have performed tests with improved radiation shields and new wind sensor designs. A magnetometer has been added to determine bird orientation and to improve wind vector calculations. We are further characterizing the accuracy of the temperature measurements under pseudosimulated flight conditions using heating pads on decoy birds mounted on a vehicle. Thermal IR imagery from this study qualitatively informs the experimental design. We think, with similar continued calibration and testing, our use of avian bioplatforms has the potential to fill a measurement niche for research applications in, and beyond, the urban area.

ACKNOWLEDGMENTS. We thank first Freedom Conservation for the use of and assistance with WTE (Victor) and SIE (Daschan). We also wish to acknowledge the Scottish Executive, Scottish Natural Heritage, the Royal Society for the Protection of Birds, and particularly the Applecross Estate, for its assistance and negotiations permitting this experiment to occur. We are grateful to Ed Chung for his voluntary assistance with Python coding. This work is supported by the NERC Grant NE/N003195/1.

\section{REFERENCES}

Austen, K., 2015: Environmental science: Pollution patrol. Nature, 517, 136-138, https://doi.org/10 $.1038 / 517136$.

Barlow, J. F., 2014: Progress in observing and modelling the urban boundary layer. Urban Climate, 10, 216-240, https://doi.org/10.1016/j.uclim.2014.03.011.

— C. H. Halios, S. E. Lane, and C. R. Wood, 2015: Observations of urban boundary layer structure during a strong urban heat island event. Environ. Fluid Mech., 15, 373-398, https://doi.org/10.1007 /s10652-014-9335-6. 
Bird, D. M., D. E. Varland, and J. J. Negro, Eds., 1996: Raptors in Human Landscapes: Adaptation to Built and Cultivated Environments. Academic Press, $396 \mathrm{pp}$.

Cocker, M., 2013: Birds and People. Jonathan Cape, $592 \mathrm{pp}$.

Elliott, K. H., 2016: Measurement of flying and diving metabolic rate in wild animals: Review and recommendations. Comp. Biochem. Physiol., 202A, 63-77, https://doi.org/10.1016/j.cbpa.2016.05.025.

Fehlmann, G., and A. J. King, 2016: Bio-logging. Curr. Biol., 26, R830-R831, https://doi.org/10.1016/j .cub.2016.05.033.

Gillies, J. A., A. L. R. Thomas, and G. K. Taylor, 2011: Soaring and manoeuvring flight of a steppe eagle Aquila nipalensis. J. Avian Biol., 42, 377-386, https:// doi.org/10.1111/j.1600-048X.2011.05105.x.

Greatwood, C., and Coauthors, 2017: Atmospheric sampling on Ascension Island using multirotor UAVs. Sensors, 17, 1189, https://doi.org/10.3390/s17061189.

Lewis, A., and P. Edwards, 2016: Validate personal airpollution sensors. Nature, 535, 29-31, https://doi.org /10.1038/535029a.

Pelliccioni, A., P. Monti, C. Gariazzo, and G. Leuzzi, 2012: Some characteristics of the urban boundary layer above Rome, Italy, and applicability of Monin-Obukhov similarity. Environ. Fluid Mech., 12, 405-428, https://doi.org/10.1007/s10652-012-9246-3.

Portugal, S. J., and Coauthors, 2014: Upwash exploitation and downwash avoidance by flap phasing in ibis formation flight. Nature, 505, 399-402, https://doi .org/10.1038/nature12939.

Reuder, J., M. O. Jonassen, and H. Ólafsson, 2012: The Small Unmanned Meteorological Observer SUMO: Recent developments and applications of a micro-UAS for atmospheric boundary layer research. Acta Geophys., 60, 1454-1473, https://doi .org/10.2478/s11600-012-0042-8.

Roth, M., 2000: Review of atmospheric turbulence over cities. Quart. J. Roy. Meteor. Soc., 126, 941-990, https://doi.org/10.1002/qj.49712656409.

Shepard, E. L. C., C. Williamson, and S. P. Windsor, 2016: Fine-scale flight strategies of gulls in urban airflows indicate risk and reward in city living. Philos. Trans. Roy. Soc., 371B, 20150394, https://doi. org/10.1098/rstb.2015.0394.

Tennekes, T., 1996: The Simple Science of Flight: From Insects to Jumbo Jets. MIT Press, $152 \mathrm{pp}$.

Thomas, A. L. R., 1993: On the aerodynamics of birds' tails. Philos. Trans. Roy. Soc. London, 340B, 361-380, https://doi.org/10.1098/rstb.1993.0079.

Treep, J., G. Bohrer, J. Shamoun-Baranes, O. Duriez, R. Prata de Moraes Frasson, and W. Bouten, 2016: Using high-resolution GPS tracking data of bird flight for meteorological observations. Bull. Amer. Meteor. Soc., 97, 951-961, https://doi.org/10.1175 /BAMS-D-14-00234.1.

Vandenabeele, S. P., E. Grundy, M. I. Friswell, A. Grogan, S. C. Votier, and R. P. Wilson, 2014: Excess baggage for birds: Inappropriate placement of tags on gannets changes flight patterns. PLoS One, 9, e92657, https://doi.org/10.1371/journal.pone.0092657.

Wilcox, E. M., R. M. Thomas, P. S. Praveen, K. Pistone, F. A. M. Bender, and V. Ramanathan, 2016: Black carbon solar absorption suppresses turbulence in the atmospheric boundary layer. Proc. Natl. Acad. Sci. USA, 113, 11 794-11 799, https://doi.org/10.1073 /pnas.1525746113. 
Hurricane Pioneer:

Memoirs of

Bob Simpson

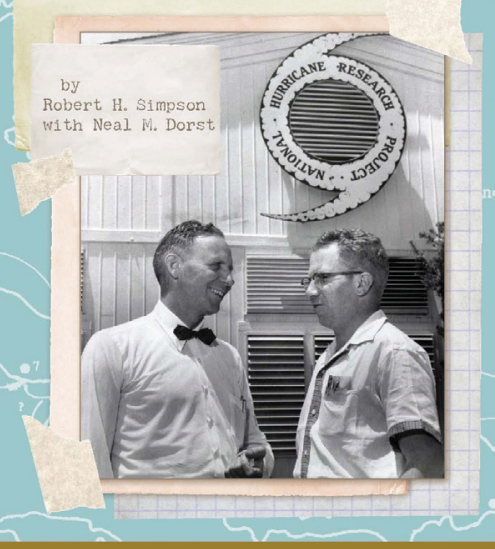

AMERICAN METEOROLOGICAL SOCIETY

Browse online at ametsoc.org/bookstore

FREE SHIPPING for AMS Members!

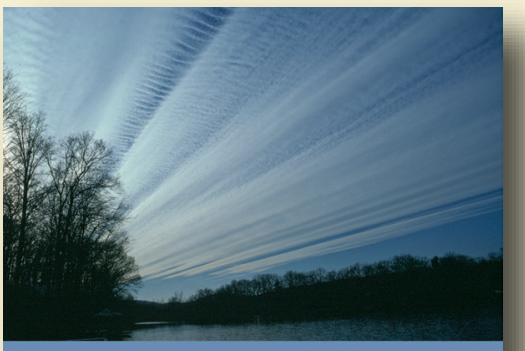

AN OBSERVER'S GUIDE to

CLOUDS AND WEATHER

A NORTHEASTERN PRIMER ON PREDICTION TOBY CARLSON, PAUL KNIGHT, AND CELIA WYCKOFF

\section{HURRICANE PIONEER}

Memoirs of Bob Simpson

Robert H. Simpson with Neal M. Dorst

In 1951, Bob Simpson rode a plane directly into the wall of a hurricane-just one of his many pioneering explorations. This autobiography of the first director of the National Hurricane Research Project and co-creator of the SaffirSimpson Hurricane Scale starts with childhood rememmbrance and ends in first-hand account of a revolutionary

(C) 2014, PAPERBACK

ISBN: 978-1-935704-75-1

LIST \$30 MEMBER \$20
William B. Gail

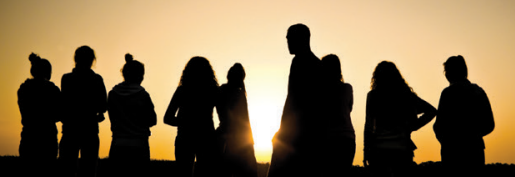

CLIMATE

CONUNDRUMS

What the Climate Debate Reveals About Us

\section{CLIMATE CONUNDRUMS} What the Climate Debate Reveals About Us

William B. Gail

This is a journey through how we think, individually and collectively, derived from the climate change debate. With wit and wisdom, Gail explores several questions: Can we make nature better? Could science and religion reconcile? Insights from such issues can help us better understand who we are and help

(c) 2014, PAPERBACK

ISBN: 978-1-935704-74-4

LIST \$30 MEMBER \$20
AMERICAN METEOROLOGICAL SOCIETY

\section{AN OBSERVER'S GUIDE TO CLOUDS AND WEATHER}

A Northeast Primer on Prediction

Toby Carlson, Paul Knight, and Celia Wyckoff

With help from Penn State experts, start at the beginning and go deep. This primer for enthusiasts and new students alike will leave you with both refined observation skills and an understanding of the complex science behind the weather: the ingredients for making reliable predictions of your own.

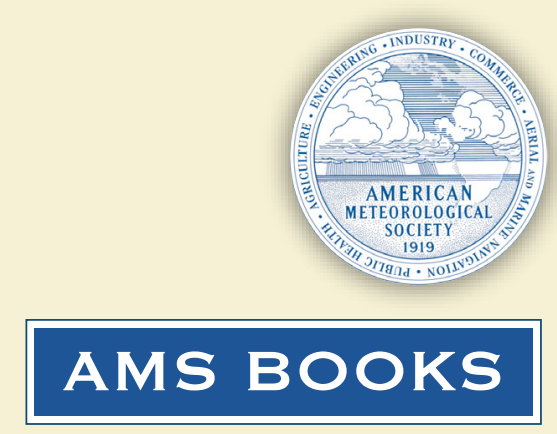

AMS Books are available to groups and booksellers, and desk copies may be obtained, through our distributor 